\title{
Adolescência e Tendência Antissocial: o Rap como Expressão de uma Privação Emocional
}

Adolescence and an Antisocial Tendency: Rap as an Expression of Emotional Deprivation

Adolescencia y Evolución Antissocial: el Rap como Expresión de Privación Emocional

Cláudia Yaísa Gonçalves da Silva \& Rute Grossi Milani

Universidade de São Paulo 
Resumo: Opresenteestudo objetiva refletir sobre a tendência antissocial noadolescente/jovem, por meio da análise do conteúdo descrito nas letras de músicas de rap brasileiro, as quais em geral surgem carregadas de revolta, inconformismo, denúncias sociais e esperança. A pesquisa se caracteriza como exploratória, documental e qualitativa. Para tanto, foi realizada análise de conteúdo das letras, e posterior discussão embasada na teoria de Donald Woods Winnicott, buscando nos trechos das músicas indícios referentes a privações ambientais e o sentido que as letras carregam no contexto do comportamento antissocial. Na análise de conteúdo encontraram-se três categorias: a falha ambiental como princípio para a tendência antissocial, a tendência antissocial enquanto esperança de reparação, e o rap para além da música. Nos excertos das letras de rap selecionadas, os comportamentos antissociais mostraram-se enquanto saída emocional encontrada pelos adolescentes/jovens com histórico de privação, fazendo-os adotarem uma conduta desafiadora socialmente como forma de buscar uma contenção externa para reparar a falha vivenciada antes por alguma figura referencial. Conclui-se que o rap se instaurou como solução positiva para a expressão dos sentimentos e a conquista de uma identidade e reconhecimento social frente aos pares.

Palavras-chave: Winnicott. Adolescência. Comportamento Antissocial. Privação.

\begin{abstract}
This study considers antisocial behavior in adolescents and young people by analyzing the content of the lyrics of Brazilian rap, which generally includes revolt, discontent, social complaint, and hope. The research is characterized as exploratory, qualitative, and documentary. We analyzed the content of letters and further discussion based on the theory of Donald Woods Winnicott, seeking clues in the context of antisocial behavior in verses of songs associated with environmental deprivation and the sense present in letters. Content analysis revealed three categories: environmental failure as a principle for antisocial behavior, antisocial behavior as a hope for repair, and beyond rap music. The antisocial behavior revealed excerpts of selected rap lyrics, while emotional output was found by adolescent/young people with a history of deprivation, causing them to adopt socially challenging behavior as a way of seeking an external wrapping for repairing the failure experienced before by some figure of reference. We conclude that rap is introduced as a way of expressing positive feelings and gaining an identity and social recognition of peers.
\end{abstract}

Keywords: Winnicott. Adolescence. Antisocial Behavior. Deprivation.

Resumen: En este estudio se analiza la tendencia de los adolescentes/jóvenes antisociales, mediante el análisis de los contenidos descritos en las letras de rap brasileño, que por lo general viene cargado de angustia, descontento, quejas sociales y esperanza. La investigación se caracteriza por ser exploratoria, cualitativa y documental. En ese sentido, se analizó el contenido de las letras y se discutió sobre la base de la teoría de Donald Woods Winnicott, buscando pistas en los pasajes de canciones relacionadas con la privación del medio ambiente y el sentido que las letras tienen en el contexto de la conducta antisocial. El análisis de contenido encontró tres categorías: insuficiencia del medio ambiente como principio de la conducta antisocial, la conducta antisocial como la esperanza de la reparación, y por último, la música rap. En extractos de selección de letras de rap, el comportamiento antisocial se presentó evidenciando la producción emocional de en adolescentes/jóvenes con antecedentes de privación, quienes adoptan una conducta socialmente desafiante como una manera de buscar una protección externa para reparar el fracaso experimentado por alguna figura de referencia. Llegamos a la conclusión que el rap se introduce como una solución a la expresión de sentimientos positivos y la obtención de una identidad y reconocimiento social contra pares.

Palabras clave: Winnicott. Adolescencia. Conducta Antisocial. Privación. 


\section{Introdução}

O tema da adolescência e as tendências antissociais, principalmente a delinquência e os desvios de conduta, têm sido objeto de investigação em muitos estudos da área da Educação, Psicologia e do Direito. Em geral, as pesquisas se delimitam ao contexto social do adolescente de classe baixa, da periferia, em conflito com a lei. Steffen (2006) descreve semelhanças envolvendo os adolescentes que frequentam instituição judiciária devido a processos de atos infracionais. Em sua maioria são jovens de classe baixa que manifestam defasagem escolar, roubam, furtam, possuem contato com as drogas e com menor frequência há os que ainda praticam atos de homicídio.

Segundo Bordin e Offord (2000), existem fatores de risco que estatisticamente encontramse ligados ao aumento da probabilidade de manifestação do comportamento antissocial em crianças. Pode-se elencar "(...) ser do sexo masculino, receber cuidados maternos e paternos inadequados, viver em meio à discórdia conjugal, ser criado por pais agressivos e violentos, ter mãe com problemas de saúde" (p. 13). O panorama geral aponta para um ambiente desfavorável ao sujeito em que permeia a negligência, o abuso e figuras parentais fracas.

Uma análise organizada por Martins e Pillon (2008), envolvendo adolescentes internados em unidades da FEBEM de Ribeirão Preto e Sertãozinho (São Paulo), identificou que, para esses jovens, que em sua maioria viviam com apenas uma figura parental, a escola se apresentava enquanto um importante ambiente para proteger e evitar que o adolescente entrasse na delinquência, pois quanto mais cedo se tem a evasão escolar, mais cedo o jovem possui chances de cometer delito e estar em contato com as drogas.

No imaginário social perpassa a concepção de que a adolescência é uma fase problemática e que os jovens que apresentam atos desviantes possuem má índole, falta de caráter ou vingança difícil de ser controlada. Essa ideia, advinda também dos profissionais de saúde que lidam com tal clientela, vem carregada de preconceito e acaba por enfraquecer a qualidade dos serviços sociais e de saúde destinados aos jovens em conflito com a lei, pois a culpabilização pelo problema do adolescente recai nele ou no meio (família e sociedade), de forma que os profissionais não veem muita possibilidade de mudança (Pontes, 2011).

À procura de um olhar ampliado acerca dessa temática, o presente trabalho pretende enfocar os adolescentes/jovens do gênero masculino que vivem no entorno da confrontação das leis da sociedade, considerados delinquentes, antissociais ou ainda com distúrbios de conduta. Por meio do referencial winnicottiano, compreende-se que, em muitos casos, por trás da rebeldia social, pode-se encontrar a marca de uma privação emocional nos primeiros estágios do desenvolvimento do sujeito em decorrência de uma carência ambiental em algum período desse processo. Em vista disso, a conduta antissocial pode estar presente tanto em jovens de famílias pobres, quanto nos de classe média e alta, porque as falhas do meio estão sujeitas a qualquer lar (Oliveira, 2010).

Contudo, almeja-se refletir sobre a tendência antissocial no adolescente/jovem de classe baixa, por meio da análise do conteúdo descrito nas letras de músicas de rap brasileiro, as quais em geral surgem carregadas de revolta, inconformismo, denúncias sociais e esperança. Realizou-se uma análise psicanalítica baseada nos fundamentos winnicottianos, buscando nos trechos das músicas indícios referentes a privações ambientais e o sentido que as letras carregam no contexto do comportamento antissocial.

A pesquisa proposta se apresenta como relevante socialmente ao abrir a possibilidade para que o jovem antissocial excluído da sociedade seja resgatado em sua integridade físíca e emocional, que possa ser dado a ele a chance de escapar do estereótipo de menino pobre, delinquente e que proveu de uma família desestruturada, para avançar em uma reformulação de sua história, onde a ele é dada a capacidade de tomar posse de uma 
identidade pessoal e construir uma vida produtiva. Acrescenta-se a contribuição científica do trabalho pelo fato de permitir ampliar os instrumentos de investigação psicanalítica ao abarcar a adolescência e suas vicissitudes por meio de um material pouco utilizado, as letras de músicas de rap, que são formas de expressão da subjetividade humana, assim como a pintura e a literatura. Além disso, o trabalho oferece aporte para os estudos em Psicologia, a qual possui responsabilidade para com o desenvolvimento do ser humano e a sociedade, entendendo que o sujeito é fruto do contexto social, econômico e cultural do qual advém.

Primeiramente será delineada a fase da adolescência com suas peculiaridades, transformações e aquisições em nível de desenvolvimento. Após, elucidar-se-á as questões tangentes à tendência antissocial abrangendo a delinquência e os comportamentos transgressores. Será esclarecida a origem e desenvolvimento da tendência antissocial, com possibilidades de ação benéfica e reversão do quadro. Por último, acrescenta-se uma breve compreensão do gênero musical rap, seguido da análise de alguns excertos de músicas desse estilo musical que revelam a representação de aspectos contribuintes para a manifestação de comportamento antissocial.

\section{Revisão da Literatura}

\section{O Limiar entre a Adolescência Saudável e a Antissocial}

$\mathrm{Na}$ adolescência ou juventude acontecem as conhecidas mudanças fisiológicas com reflexos visíveis no corpo do indivíduo. Porém, modificações psicológicas e sociais também se fazem presentes nesse período. Erikson (1971) pontua que o adolescente se aproxima cada vez mais da vida adulta, sendo constantemente convidado a assumir tarefas e posicionar-se enquanto tal. Preocupa-se com o que os outros pensam que ele é, comparando-se ao juízo que faz de si mesmo. Aos poucos a identidade se torna mais estruturada por meio da proximidade da integração egoica.
O adolescente não se conforma com o papel preestabelecido a si pelos adultos, ao mesmo tempo em que não sabe no que se tornará, quer trilhar seu próprio caminho. Sentindo-se incapaz de assumir os papéis sociais impostos, não é raro o jovem que se ausenta de uma ou outra forma, deixa a escola, passa a noite fora de casa, abandona o emprego, recolhe-se em si mesmo de forma a se distanciar dos outros (Winnicott, 2005). Tal adolescente pode ficar fadado a estigmatização de parte da sociedade, caso esteja envolto por juízos sociais que desconheçam ou desprezam as condições específicas e dinâmicas dessa etapa do desenvolvimento (Erikson, 1972).

O jovem naturalmente passa por uma fase adaptativa de comportamentos transgressores às normas sociais. Isso acontece como um meio de organizar o caos interno a que o adolescente está submetido, pois sua personalidade está em estruturação, sofre as pressões da família para assumir responsabilidades, ao mesmo tempo em que deseja experimentar coisas novas para definir sua individualidade. Dessa forma, ao transgredir, o sujeito movimenta uma série de figuras de autoridade (pais, professores, policial) para agirem no sentido de contê-lo externamente, auxiliando consequentemente no controle interno (Benavente, 2002).

Winnicott (2005) revela a existência de uma íntima relação entre as dificuldades normais da adolescência e a tendência antissocial. Na origem desta, há sempre uma privação ocorrida em um momento prematuro que acaba por abalar as defesas do sujeito. A criança antissocial procura fazer com que o meio repare a dívida que tem com ela por ter causado tal privação, levando-a a enfrentar a sociedade como em um pedido de ajuda. Na adolescência também aparecem aspectos dessa carência, mas na maioria das vezes de forma sutil. O que pode acontecer é o adolescente se identificar com um grupo em que um representante se coloca como provocador da sociedade, de forma que o próprio adolescente não aprovaria tal atitude em si, mas se identifica com o desvio de conduta do outro buscando auto afirmar-se. 
Por um viés o adolescente saudável é imaturo e irresponsável, pois está em processo de estruturação e afirmação de si. A imaturidade "é uma parte preciosa da adolescência. Ela contém as características mais fascinantes do pensamento criativo, sentimentos novos e desconhecidos, ideias para um modo de vida diferente" (Winnicott, 1989, p. 126). Mas a imaturidade não está presente todo o tempo, com o passar dos anos e a proximidade da fase adulta, espera-se que se alcance a maturidade tão almejada e cobrada pelos adultos, sem atropelos, sem pular etapas, pois ao contrário desembocaria em adolescentes com falsa maturidade.

Acima de tudo não se pode esquecer que esse período é complicado e com constantes mudanças, sendo em certos casos vivenciado com angústia e ansiedade. Precisa-se deixar o corpo, os pais e a vida infantil para trás, elaborar esse luto e se deparar com o surgimento de um corpo adulto, com responsabilidades, dúvidas e incertezas que antes não faziam parte da vida do adolescente.

\section{Compreendendo a Tendência Antissocial}

Posteriormente à elucidação referente à fase da adolescência, faz-se possível contemplar a noção de tendência antissocial, primordial para respaldar a discussão e análise proposta nessa pesquisa sobre as condutas antissociais manifestadas na fase da adolescência.

Winnicott (1982) expõe que a tendência antissocial pode ser observada mesmo em crianças normais e é originada sempre de uma privação emocional. Essa conduta demonstra uma tendência do sujeito a querer retornar ao período anterior à privação, onde houve uma perda de algo que foi bom para ele em determinado momento e foi, então, retirado por um período considerável.

Na fase da dependência absoluta da criança (após o nascimento), a mãe deve exercer sua função materna sendo devotada a seu filho e estabelecer com ele uma relação muito próxima de entrosamento. Nota-se que esta fase é normal e necessária para o existir do bebê (Vilhena \& Maia, 2002). Naturalmente, conforme o amadurecimento da criança, a mãe deixa de atender todas as suas demandas, inserindo pequenas falhas que vão apontando para o infante a diferenciação entre ele, a mãee o mundo externo (fase de dependência relativa).

O que acontece em alguns casos é que a criança pequena vivencia uma sucessão de rupturas provenientes do ambiente em um momento ainda prematuro de seu desenvolvimento, em que não internalizou aspectos protetores e de segurança em si, necessitando de protetores e referenciais externos. A criança nessa situação, desprovida de um bom ambiente interno, sente-se angustiada, desamparada por perceber que o quadro de referência de sua vida não a sustentou, levando-a a buscar estabilidade externa, fora de casa, nos avós, tios, vizinhos, escola e amizades (Winnicott, 2002).

A falha real do ambiente no amparo ao ego da criança é mencionada por Winnicott (1982) como privação emocional ou de-privação, a qual provoca um bloqueio no desenvolvimento emocional saudável do sujeito. Em decorrência dessa eventualidade, observa-se por parte da criança a esperança de que o meio se dê conta da ruptura imposta e repare a fenda específica provocada pelo dano, agarrando-se ao pequeno indício de sobrevivência de um meio protetor. Assim, a partir de pulsões inconscientes o sujeito reivindica cuidado, compreensão e tolerância por parte do outro.

Dependendo do momento e da intensidade na vida do sujeito em que a privação se inseriu, poderão se desenvolver diferentes respostas. Neste tocante, caso a criança desde o início de suas relações com as figuras parentais vivenciou um desprovimento significativo de presença, olhar, cuidado, controle e sustentação de seus conteúdos internos, poderá tornar-se um sujeito frio, indiferente e com características depressivas (tendência psicótica). Contudo, se a mesma experienciou momentos prazerosos e agradáveis nos períodos iniciais da vida e depois ficou desprovida desse aparato por uma privação emocional, a resposta mais provável será a apropriação de comportamentos antissociais (Sá, 2001). 
O esperado é que as pessoas passem por frustrações na infância, no entanto, o que vale atentar é para a intensidade com que acometeu a vida de cada um, porque se foi demasiado, possivelmente acarretará marcas dolorosas. Quando se pretende obter uma compreensão mais bem apurada acerca da adolescência, é elementar que se faça um retorno ao modo como se desenrolou o desenvolvimento do sujeito na primeira infância. Isto posto, uma decepção para com as figuras parentais nessa fase anterior, pode suscitar uma resposta violenta na juventude, tanto em sujeitos saudáveis, quanto naqueles considerados vulneráveis, enquanto um reclame pela frustração vivenciada (Dayan, Bernard, Olliac, Mailhes \& Kermarrec, 2010).

Em alguns casos, a própria família ou responsáveis percebem a fenda e organizam meios de compensá-la, fazendo uso de mimos, manejo especial, controle por alguém afetuoso ou o denominado amamentar mental, conduzindo ao restabelecimento maturacional. No entanto, se isso não acontece, o indivíduo pode prolongar-se em uma constante prisão emocional ou atuar (acting out) mantendo a esperança de que será possível forçar o ambiente a ressarcir o dano (Winnicott, 1982). Nesses casos, a autoridade máxima a que o jovem inconscientemente incita a lhe dar estabilidade é a instituição judicial, vista até mesmo pelos responsáveis por jovens infratores, como a última esperança para o controle e educação dos mesmos (Dias, Arpini \& Simon, 2011).

Em acréscimo, Winnicott (2002) sugere o quanto a psicoterapia também pode ser um auxiliador no sentido de proporcionar a continuidade saudável do desenvolvimento emocional da criança e do adolescente, por meio de experiências que possibilitem certa compreensão da realidade, integração da personalidade, o poder suportar frustrações e fazer reparações. Isso tudo capacitando o sujeito a lidar com as intercorrências que poderão ocorrer na vida, como um pai alcoólatra e uma mãe deprimida.

Pelo mesmo viés, Rotondaro (2002) reconheceu a importância da atividade psicoterápica do brincar a partir de um trabalho com 25 meninos de um abrigo desprovidos de pais e com comportamentos antissociais. A partir do contexto lúdico, os garotos ganharam voz, puderam expressar seus sentimentos e vivenciar experiências de criatividade, individualidade, confiança e controle. Um dos resultados partiu de um grupo de meninos que decidiu levar para os encontros terapêuticos, letras de rap com as quais se identificavam, manifestando o desejo de montar um grupo de música. Por meio do trabalho desenvolvido, pode-se refletir que sua função foi de proporcionar aos meninos abrigados uma vivência construtiva e diferente do sofrimento instalado na história de cada um deles, sendo respeitados e acolhidos.

Nesse momento, faz sentido acrescentar a noção de transicionalidade difundida por Winnicott, para correlacionar às possibilidades que um sujeito encontra para representar sua subjetividade. Braga (2012), a partir da perspectiva winnicottiana, explica a questão da transicionalidade como uma experiência entre o mundo subjetivo da fantasia e o mundo objetivo da realidade. Trata-se de um campo intermediário entre o real e o imaginário, estando em relação com o significado da criatividade, da brincadeira, da arte e da religião.

Winnicott (1971) inicialmente insere os termos objetos e fenômenos transicionais para esclarecer essa zona que não pertence nem à realidade interna do bebê nem à externa, mas à transição do período em que o infante se mantém fundido à mãe para outro momento em que inicia sua diferenciação. Nessa etapa inicial da vida, os fenômenos transicionais carregam a função de dar suporte ao bebê perante suas angústias quando da ausência das figuras de referência (pais, cuidadores).

Na infância, a criança faz uso de objetos escolhidos por si mesma para desempenhar o papel desse espaço potencial, como ursos de pelúcia e paninhos. Já na adolescência, surgem outros substitutos para a transicionalidade, apontados nos jogos, na escrita e na fala. Em seu estudo sobre a prática do escrever para os adolescentes, Braga (2012) 
encontrou que por meio da escrita e inscrição de poemas e músicas em diários, blogs e na rede social, essa juventude encontra um meio de criar um espaço transicional para evidenciar o que se passa em seu mundo interno, os conflitos, a busca de uma identidade e o processo de amadurecimento. A escrita adquire, assim, a possibilidade do sujeito ser alguém a partir de sua produção, uma forma de comunicar algo.

Em face do que foi apresentado neste tópico, é plausível evidenciar que a tendência antissocial carrega a marca de uma privação emocional no indivíduo, o qual, frente a poucos recursos psíquicos existentes, força inconscientemente o outro a destinar para si, atenção, cuidado e estabilidade.

\section{O Ambiente Familiar}

Considera-se a família enquanto importante ambiente para o desenvolvimento da criança, na maioria dos casos é a primeira instituição a que o infante se depara para aprender sobre o mundo. Para Winnicott (1989), os pais comuns considerados bons, são aqueles que fundam um lar e buscam mantê-lo oferecendo os cuidados básicos ao desenvolvimento saudável dos filhos.

Observa-se atualmente uma queda na função paterna, exposta na dificuldade dos pais em se colocarem como representantes da lei em uma família (Araújo, 2005). Contudo, também a mulher está envolta por fatores que impedem o estabelecimento de uma devoção e cuidados primários a seu bebê, seja por uma família patológica ou por relacionamentos afetivos violentos (Saes, 2012). Diante disso, o sujeito desamparado pode fazer uso de sua agressividade hostil, gritar, extrapolar os limites e fazer tudo que esteja ao seu alcance para solicitar que reparem nele, pois, enquanto perdurar a esperança, irá incansavelmente incomodar (Vilhena \& Maia, 2002).

Em seu estudo, Hennig (2008) percebeu que as práticas educacionais dos pais aos seus filhos são influenciadas pela memória da qualidade dos cuidados recebidos na própria infância. Quando se está diante de uma carência nas funções parentais na condução dos atos de um filho, o mesmo vê-se perante o desamparo, o qual propicia a imersão nos comportamentos antissociais como via de fazer-se ser controlado pelo meio. Do mesmo modo, Calkins e Keane (2009) identificaram na criança a influência precoce do contexto familiar e dos relacionamentos iniciais, como moderadores para o surgimento da tendência antissocial.

Outeiral e Cerezer (2003) também discorrem acerca do peso que a família possui na constituição psíquica dos adolescentes excluídos socialmente. Em uma grande maioria de famílias, encontra-se a ausência da figura paterna enquanto elemento organizador e limitador do sujeito. Por isso, é comum o jovem com comportamentos transgressores tomar para si um chefe poderoso de gangue como representante da figura paterna que não se faz presente na vida do adolescente. Steffen (2006) fomenta poder acontecer, ainda, de o jovem assumir dentro de casa a posição do pai, exercendo a lei frente aos irmãos menores e ajudando a mãe na sustentação do lar, tanto pela ausência paterna quanto pela debilidade dessa imagem quando esta se encontra presente.

A respeito da realidade dos países em desenvolvimento, considera-se que as interferências sociais, econômicas e familiares impostas a crianças que vivem em condições inadequadas de vida desde um estágio inicial do desenvolvimento, podem levá-las mais tarde a viverem no limiar entre as condutas legais e as transgressões sociais. Em meio a isso, na adolescência, alguns se afiliam a grupos criminosos buscando criar laços sociais e afirmar uma identidade (Leite, Saggese, Leite, Kassab, Manhães et al., 2009).

Em vista de tudo que foi exposto, vale ressaltar que, mesmo os pais tentando prover os filhos da melhor forma possível, poderá haver erros que talvez sejam sentidos pelos menores como significativos. Tais impasses muitas vezes são difíceis de ser controlados; no entanto, uma família, cuidadores ou responsáveis atentos, podem reparar as 
falhas e promover para a criança/adolescente uma experiência positiva, diferente da vivenciada anteriormente.

\section{Método}

A pesquisa se caracteriza como exploratória, documental e qualitativa. Para o desenvolvimento da mesma foram elencados como materiais da pesquisa, letras de músicas de rap brasileiro, das quais foram selecionados trechos manifestando conteúdo referente a uma privação vivenciada pelo indivíduo que pudesse revelar tal evento enquanto uma falha ambiental marcante e contribuinte para a aproximação com a delinquência e atos antissociais na adolescência/juventude. A coleta dos dados foi realizada via Internet, em sites que disponibilizam letras de músicas de diversos grupos musicais. Por meio da análise de conteúdo, foi possível aprofundar a compreensão musical para além do discurso explícito e tentar extrair o significado que as letras representariam para cada um dos compositores escolhidos e a mensagem subjacente emergente, considerando o contexto histórico, cultural e econômico em que passaram a infância e adolescência e as diversas experiências experienciadas ao longo da vida. Segundo Bardin (1977), a análise de conteúdo permite ao pesquisador entendimento das representações que o indivíduo tem sobre sua realidade e a interpretação que faz dos significados a sua volta. Posteriormente, procedeu-se uma análise psicanalítica winnicottiana acerca dos conteúdos presentes nas letras musicais que puderam indicar a relação com o meio segundo uma privação emocional proveniente da relação com as figuras parentais e o ambiente.

\section{Resultados e Discussão}

Tendo introduzidas as principais dimensões teóricas a serem abordadas na atual pesquisa, pode-se acrescentar os aspectos alusivos ao rap, gênero musical que oferecerá enriquecimento material para a composição da análise proposta à luz da teoria winnicottiana.
Rap significa "rhythm and poetry" (ritmo e poesia). Este gênero musical teve origem na Jamaica e chegou aos Estados Unidos, em 1970, atrelado aos protestos dos jovens negros das periferias. O rap é parte de um movimento maior denominado Hip Hop e carrega a marca da batida rápida, letra em forma de discurso e os passos de dança, como o break. Tanto nos Estados Unidos quanto no Brasil, o rap incorporou a característica de denúncia social por meio de temas de cunho político, racial e das diferenças de classes econômicas, retratando a vivência das comunidades pobres em contraponto à satirização dos costumes da sociedade em geral (Lourenço, 2002).

Por essa via, busca-se reconhecer que as letras de rap podem retratar o contexto de um significativo número de adolescentes/ jovens do âmbito brasileiro, imersos em uma história de vida permeada por perdas, negligência e um ambiente prejudicial ao seu desenvolvimento. Tais antecedentes facilitam que os mesmos encontrem na tendência antissocial a esperança de serem vistos pela sociedade, reconhecidos enquanto indivíduos de desejo, nem que seja pela identificação de delinquente. Além de tais aspectos, a música é entendida aqui como um processo criativo de reparo dos danos e exteriorização do acúmulo de experiências de uma vida difícil.

Para a análise de conteúdo foram elencadas três categorias: a falha ambiental como princípio para a tendência antissocial, a tendência antissocial enquanto esperança de reparação, e o rap para além da música.

\section{A falha ambiental como princípio para a tendência antissocial}

Na letra de rap a seguir, expõe-se a denúncia de um jovem vindo de uma família com vínculos precários e falta de subsídios econômicos, os quais possivelmente instalaram falhas que a algum nível ficaram registradas no psiquismo do sujeito. "Nunca ninguém me deu um ponto positivo. Quando fui roubar, me chamaram de agressivo. Vim de uma família desestruturada. Que a fome fez da mãe de 
um homem uma empregada" (Brinquedo Assassino - A Família).

Leite et al. (2009) aponta que uma qualidade precária nas condições sustentáveis de vida e nos vínculos familiares acrescentam maior probabilidade de o sujeito entrar na fronteira entre as normas legais e as infrações. Como defesa contra o desamparo emocional e material, pode-se cogitar que o jovem da música passa a assumir uma posição agressiva frente aos outros, ressaltando que ao longo de sua vida ninguém o viu de forma positiva. $\mathrm{O}$ uso da agressividade como um caminho de esperança para ser visto pelo outro é citado por Vilhena e Maia (2002), que afirmam o quanto a criança irá usar desse tipo de artifício para incomodar o adulto e exigir que the deem atenção.

O adolescente/jovem que cresce sem figuras de referência sustentáveis, acaba, por vezes, solto no mundo, até o momento em que pode se deparar com a delinquência e os atos antissociais, onde ao menos assume uma identidade frente a um grupo. Isso pode ser verificado na seguinte letra: "Eu vi sua conquista em seu primeiro oitão. $\mathrm{O}$ tempo passa, o crime cresce sem noção, irmão. Sem pai, sem mãe, sem noção da vida. É Deus no céu menor na fita que é pra trinca com os trinta" (Você faz falta - Mt das Ruas).

No excerto, o jovem carente de figuras parentais conseguiu reconhecimento em seu meio social quando tomou posse da sua primeira arma de fogo (oitão). Cogita-se, ainda, que dentro desse contexto social a conquista da arma poderia se assemelhar a um jovem que entra na universidade ou consegue seu primeiro emprego e recebe méritos por tal feito. Outeiral e Cerezer (2003) relacionam a valorização que os jovens desse meio possuem entre seus pares, que os levam a tomarem como referência aquele que se destaca por sua posição superior dentro do grupo.

\section{A tendência antissocial enquanto esperança de reparação}

O ambiente familiar e social hostil e prejudicial ao bom desenvolvimento de um jovem, pode ser vislumbrado em uma narrativa que se repete em diversos lares da periferia brasileira, por vezes desembocando em uma juventude com comportamentos antissociais como indício de esperança de que o meio se dê conta do erro implantado e repare a falta.

No trecho a seguir, o compositor revela o meio familiar ameaçador a que um jovem esteve inserido quando criança perante um pai adicto desempregado e agressivo, que pelo vício deixa de sustentar a posição de segurança frente à esposa e os filhos, imprimindo na família uma imagem de desgosto e revolta:

Como você não foi homem, trocou sua família pela garrafa. Morreu com o mesmo Oitão que me dava coronhada. Foi na época de escola que ele mais me batia. Mostrei os machucados pro professor. Na esperança que alguém me livrasse do purgatório. Que o juiz tomasse a guarda e eu fosse pro reformatório. Não esperei a próxima surra, fugi de casa. Deixei minha mãe sozinha. Fugiu um menino inofensivo, voltou um homem agressivo (Um Gole de Veneno - Facção Central).

No excerto exposto, verifica-se que o jovem cansado das agressões paternas destinou na escola e no juiz a esperança de que alguém tomasse frente e colocasse um fim no sofrimento a que passava diante do pai. Winnicott (1982) circunda o fato de o sujeito desamparado ir em amplitude em busca de algo que o retenha, atrelando-se a qualquer coisa que para ele se assemelha a proteção, escola, vizinhos, polícia. Dias, Arpini e Simon (2011) reiteram a sólida função que a lei jurídica ocupa perante a juventude antissocial, ocupando o lugar do pai que na vida do sujeito se mostrou ausente ou fraco. Além disso, na música exibida supõe-se a existência de uma figura materna impotente diante de um esposo com problemas, a qual não conseguiu impedir a violência dentro de casa, favorecendo o filho buscar ajuda no meio externo.

Quando se fala na permanência da tendência antissocial na adolescência, entende-se 
que a falha emocional inscrita na infância daquela pessoa não foi reparada até então, de modo que o sujeito desamparado encontra nas transgressões sociais a última esperança de que algo o limite, como apresentado no próximo fragmento:

E dentro da Febem aquele menor foi parar. Então quando estava na rua. Não tinha ninguém pra te orientar. Fazer sua matrícula na escola. Para ele poder estudar. $E$ que ninguém nada fez para sua situação melhorar. E, por enquanto, que as pessoas da alta sociedade viviam discriminando a classe pobre, mas eles nada fez, eles nada faz para a situação do nosso país mudar (Oração ao Pai Detentos do Rap).

Analisando a letra, observa-se um jovem abandonado socialmente, desprovido de figuras parentais fortes ou substitutos que o orientasse na vida, fato que contribuiu para que o menor acabasse apreendido por uma entidade externa, a Febem. Calkins e Keane (2009) afirmam o quanto as relações precoces com o ambiente familiar influenciam se um sujeito poderá adentrar nos desvios de conduta posteriormente. $\mathrm{O}$ sujeito abandonado pelas figuras referenciais se vê perdido, mas tendo esperança de uma reparação, parte inconscientemente para a tendência antissocial (Winnicott, 2002). Na música, é possível assinalar que ninguém olhou para o sujeito, até mesmo a alta sociedade, a qual teoricamente poderia fazer algo pela posição que ocupa, não se importou com as necessidades do jovem.

No mesmo sentido, a falha emocional a que uma criança é exposta prematuramente no ambiente familiar, se não for ressignificada, imprime na adolescência, em algumas situações, uma possível fuga na vida do crime, como na passagem: "Família, sem estrutura, amor em extinção. O crime se apresenta como a melhor solução" (O Choro de Uma Mãe - Shekinah Rap). Para Dayan et al. (2010), uma desilusão inserida pelos pais pode levar a uma adolescência violenta como resposta à marca registrada anteriormente.

\section{O rap para além da música}

Pode-se contemplar que o rap tem a oportunidade de, além de denunciar as desigualdades sociais, ser uma via de exteriorização dos sentimentos dos compositores desse gênero musical, os quais em sua grande maioria viveram parte da infância e adolescência em comunidades pobres, onde não raro permeia a carência material, vínculos familiares precários e condutas infratoras.

No próximo fragmento, é salientado o significado que o rap pode ter assumido na vida do compositor. "Se eu tivesse tido chance, seria jogador. Cantor de rap pra expressar minha dor" (Brinquedo Assassino - A Família). O sonho de infância que apontava para o desejo de possivelmente ser jogador de futebol não se concretizou, mas o jovem, ao se tornar cantor de rap, encontrou uma via para manifestar seus sentimentos, suas experiências, dificuldades e sonhos.

Nesse sentido, Rotondaro (2002) indica em seu estudo com meninos abrigados, o quanto a identificação dos mesmos com o rap surgiu espontaneamente com um caráter terapêutico, conjecturando que os meninos procuraram na música uma forma benéfica de dar vazão aos conteúdos pessoais e de seu cotidiano.

"Eu que tava ali no meio só posso dizer que eu fui salvo pelo RAP. Enorme satisfação, em várias cidades, eu pude passar. Eu me arrepio, é da rua pra rua. Por cada vadio, por cada vadio! Por cada garota que vem de onde eu venho" (Se o Mundo Acabar - Rashid). Nessa passagem, evidencia-se o contentamento do cantor em fazer do rap sua salvação do destino trágico em que vários jovens da periferia acabam tendo. Ademais, o compositor exprime fazer isso por todos aqueles advindos das mesmas raízes sociais que ele, como uma prova de vitória, de conquista e exemplo a ser seguido.

Braga (2012) entende que por meio da expressão de poemas e músicas, o adolescente constrói um campo transicional criativo para comunicar exteriormente o que está 
em seu mundo interno, fortalecendo uma identidade social por meio da sua produção. Nesse sentido, o rap seria o fenômeno transicional com que muitos jovens se identificam, por anunciar vivências em comum e vislumbrar a esperança de compensação de ausências, decepções e fendas em seu âmbito emocional.

Neste tópico, foi ilustrado o valor que o rap alcançou na vida dos músicos desse gênero musical e daqueles que se identificam com o conteúdo manifesto das letras. Evidenciase, ainda, a utilização da expressão musical como uma experiência de transicionalidade, onde a criatividade ganha espaço para demonstrar experiências internas e subjetivas do ser humano.

\section{Conclusões}

A tendência antissocial na adolescência e sua relação com a privação emocional na infância foi amplamente investigada pelo psicanalista Winnicott. Posteriormente à sua contribuição teórica, outros ramos científicos passaram a relacionar indícios da conduta delinquente juvenil com as falhas ambientais. Nos estudos veiculados no campo jurídico e educacional, por exemplo, assinala-se a crescente inclusão da compreensão psicanalítica em prol da ampliação da visão do sujeito, considerando-o inserido em um contexto social, econômico e histórico.

Na vigente pesquisa, empregou-se a reflexão sobre as possíveis consequências de uma privação emocional inserida nas etapas iniciais do desenvolvimento de uma pessoa, a partir do discurso exposto em letras de rap brasileiro que revelam o contexto da juventude subsistente ao entorno antissocial.

Foi passível de compreensão, nos trechos musicais extraídos e analisados, a existência de algum elemento falho que ficou marcado na infância ou se manteve na adolescência. Principalmente uma família com vínculos deficitários, figuras parentais frágeis ou ausentes no acompanhamento dos filhos, a falta de uma figura positiva e norteadora e o abandono social, pelo qual o sujeito é tido quase como inexistente.

Assim, nos excertos das letras de rap selecionadas, os comportamentos antissociais surgem enquanto saída emocional encontrada pelos adolescentes/jovens com histórico de privação, fazendo-os adotarem uma conduta desafiadora socialmente como forma de buscar uma contenção externa para reparar a falha vivenciada antes por alguma figura referencial. Nota-se que essa juventude acaba por se associar aos jovens que estão nas mesmas condições como forma de incorporar uma identidade social e criar algum vínculo, o qual no meio anterior era rúptil. Há, ainda, a exaltação daqueles que se destacam nos atos infratores ou que se tornam os chefes das gangues, tornando-se referência para os desafiliados.

Por fim, o rap adota uma conotação positiva para os adolescentes/jovens das periferias brasileiras que, por um lado, encontram na música um caminho de visibilidade social e reconhecimento entre os membros da comunidade onde vivem e, por outro, uma via de expressão artística das vivências difíceis, privações, superações e sonhos, ligados aos resquícios da infância e os vínculos com o meio no qual cresceram.

É relevante destacar a limitação deste estudo no que diz respeito à inferência feita de que as letras que expunham privações na vida de um sujeito poderiam estar ligadas à conduta antissocial na adolescência/juventude. É fato que não se conhece a fundo o que cada compositor vivenciou durante sua vida, se houve falhas significativas ou se elas foram superadas. No entanto, avaliando que os compositores de rap possuem a característica de expor na música fatos vivenciados em suas realidades, retratando em muitos casos experiências pessoais, pôde-se dissertar uma análise a partir de suposições correlacionadas com dados equivalentes da teoria psicanalítica winnicottiana.

As conclusões expostas neste trabalho sugerem a necessidade de dar continuidade às pesquisas psicanalíticas referentes ao 
contexto dos jovens ligados à tendência antissocial, encontrando outros meios que fazem uso para dar vazão às emoções e sentimentos, além do rap, e formas de contarem sobre as vivências de privações emocionais marcadas pelo meio e pelas primeiras relações interpessoais. Com isso, pretende-se tanto compreender melhor sobre os aspectos antissociais, quanto lidar com a delinquência perante um olhar ampliado. 


\section{Cláudia Yaísa Gonçalves da Silva}

Mestranda em Psicologia Clínica pela Universidade de São Paulo, São Paulo - SP. Brasil.

E-mail: claudia.yaisa@gmail.com

\section{Rute Grossi Milani}

Doutora em Saúde Mental pela Universidade de São Paulo, São Paulo - SP. Docente do Centro de Ensino Superior de Maringá, Maringá - PR. Brasil.

E-mail: rutegrossi@uol.com.br

\section{Endereço para envio de correspondência:}

Rua Hermes da Fonseca, $n^{\circ}$ 645, Jd. Milani. CEP: 86807-060. Apucarana - PR. Brasil.

Recebido 08/07/2013, Aprovado 29/10/2014. 


\section{Referências}

A familia. Brinquedo assassino. Recuperado em 12 de abril de 2013, de http://m.letras.mus. br/a-familia/488811/

Araújo, S. M. B. (2005). A ausência da função paterna no contexto da violência juvenil. In 2o Simpósio Internacional do Adolescente, São Paulo

Bardin, L. (1977). Análise de conteúdo. Lisboa: Edições 70.

Benavente, R. (2002). Delinquência juvenil: Da disfunção social à psicopatologia. Análise Psicológica, 20(4), 637-645.

Bordin, I. A. S, \& Offord, D. R. (2000). Transtorno da conduta e comportamento anti-social. Revista Brasileira de Psiquiatria, 22, 12-15.

Braga, C. M. L. (2012). A escrita na transicionalidade e a possibilidade de ser do adolescente. Omnia Saúde, 9(1), 12-22.

Calkins, S.D., \& Keane,S.P.(2009).Developmental origins of early antisocial behavior. Development and Psychopathology, 21(4), 1095-1109.

Dayan, J., Bernard, A., Olliac, B., Mailhes, A. S., \& Kermarrec, S. (2010). Adolescent brain development, risk-taking and vulnerability to addiction. Journal of Physiology, 104(5), 279-286.

Detentos do Rap. Oração ao Pai. Recuperado em 8 de abril de 2013, de http://m.letras. mus.br/detentos-do-rap/321206/

Dias, A. C. G., Arpini, D. M., \& Simon, B. R. (2011). Um olhar sobre a família de jovens que cumprem medidas socioeducativas. Psicologia \& Sociedade, 23(3), 526-535.

Erikson, E. H. (1971). Infância e sociedade. Rio de Janeiro: Zahar.

Erikson, E. H. (1972). Identidade, juventude e crise. Rio de Janeiro: Zahar.

Facção Central. Um gole de veneno. Recuperado em 8 de abril de 2013, de http://m.letras. mus.br/faccao-central/81203/

Hennig, F. (2008). Relação entre práticas educativas parentais e memórias de cuidados na infância. Dissertação de Mestrado, Centro de Filosofia e Ciências Humanas,
Universidade Federal de Santa Catarina, Florianópolis.

Leite, L., Saggese, E. G., Leite, M. D., Kassab, M. J., Manhães, R., \& Zanchetta, M. S. (2009). Life under inequalities: The long-term impacts of the silent social child abuse. International Journal of Mental Health, 38(2), 74-90.

Lourenço, M. L. (2002). Cultura, arte, política \& o movimento hip hop. Curitiba: Chain.

Martins, M. C., \& Pillon, S. C. (2008). A relação entre a iniciação do uso de drogas e o primeiro ato infracional entre os adolescentes em conflito com a lei. Cadernos de Saúde Pública, 24(5), 1112-1120.

Mt das Ruas. Você faz falta. Recuperado em 11 de abril de 2013, de http://m.letras.mus.br/ mt-das-ruas/1364736/

Oliveira, J. A. A. (2010). Da agressividade à violência: Um estudo de caso sobre a tendência antissocial na conduta da criança. Polêm!ca, 9(2), 45-57.

Outeiral, J., \& Cerezer, C. (Orgs.). (2003). O malestar na escola. Rio de Janeiro: Revinter.

Pontes, M. L. S. (2011). A hora H: O imaginário coletivode profissionais dasaúdementalsobrea adolescência. Dissertação de Mestrado, Centro de Ciências da Vida, Pontifícia Universidade Católica de Campinas, Campinas.

Rashid. Se o mundo acabar. Recuperado em 04 de maio de 2013, de http://letras.mus.br/ rashid/2002825/

Rotondaro, D. P. (2002). Os desafios constantes de uma psicóloga no abrigo. Psicologia Ciência e Profissão, 22(3), 8-13.

Sá, A. A. (2001). Delinqüência infanto-juvenil como uma das formas de solução da privação emocional. Psicologia: Teoria e Prática, 3(1), 13-22.

Saes, D. S. (2012). O adolescente e a violência na contemporaneidade: Tentativas de compreensão a partir do referencial teórico de D.W. Winnicott. In 2o Congresso Brasileiro de Psicologia e Adolescência, São Paulo.

Shekinah Rap. O choro de uma mãe. Recuperado em 11 de abril de 2013. de http://m.letras. mus.br/shekinah-rap/1371769/ 
Steffen, M. I. M. (2006). Delinqüência: Privação, trauma e passagem ao ato. Pulsional Revista de Psicanálise, 19(188), 82-86.

Vilhena, J., \& Maia, M. V. C. M. (2002). Agressividade e violência: Reflexões acerca do comportamento anti-social e sua inscrição na cultura contemporânea. Revista Mal-estar e Subjetividade, 2(2), 27-58.

Winnicott, D. W. (1971). O brincar e a realidade. Rio de Janeiro: Imago.
Winnicott, D. W. (1982). O ambiente e os processos de maturação: Estudos sobre a teoria do desenvolvimento emocional. Porto Alegre: Artes Médicas.

Winnicott, D. W. (1989). Tudo começa em casa. São Paulo: Martins Fontes

Winnicott, D.W. (2002). Privaçãoe delinquência. São Paulo: Martins Fontes.

Winnicott, D. W. (2005). A família e o desenvolvimento individual. São Paulo: Martins Fontes. 